\title{
Can extended photoactivation time of resin-based fissure sealer materials improve ultimate tensile strength and decrease water sorption/solubility?
}

\author{
Boniek Castillo Dutra Borges ${ }^{1}$ \\ Eduardo José Souza-Júnior ${ }^{2}$ \\ Anderson Catelan ${ }^{2}$ \\ Luís Alexandre Maffei Sartini Paulillo² \\ Flávio Henrique Baggio Aguiar²
}

\begin{abstract}
Objective: This study aimed to evaluate the impact of extended photoactivation time on ultimate tensile strength (UTS), water sorption (WS) and solubility (WSB) of resin-based materials used as fissure-sealants.

Methods: A fissure-sealant (Fluroshield) and a flowable composite (Permaflo) polymerized for 20 and 60 seconds were tested. For UTS, 20 hourglass shaped samples were prepared representing two materials and two photoactivation time $(n=5)$. After $24-h$ dry-storage, samples were tested in tension using a universal testing machine at a cross-head speed of $0.5 \mathrm{~mm} / \mathrm{min}$ (UTS was calculated in MPa). For WS and WSB, 20 disks with $5 \mathrm{~mm}$ diameter and $1 \mathrm{~mm}$ height $(\mathrm{n}=5)$ were prepared and volumes were calculated $\left(\mathrm{mm}^{3}\right)$. They were transferred to desiccators until a constant mass was obtained (m1) and were subsequently immersed in distilled water until no alteration in mass was detected (m2). Samples were reconditioned to constant mass in desiccators (m3). WS and WSB were determined using the equations $m 2-m 3 / V$ and $m 1-m 3 / V$, respectively. Data were subjected to twoway ANOVA and Tukey's HSD test $(P<.05)$.

Results: There was no significant difference between materials or photoactivation times for the UTS and WS. Permaflo presented lower but negative WSB compared to Fluroshield.

Conclusions: Extended photoactivation time did not improve the physical properties tested. Fluroshield presented physical properties that were similar to or better than Permaflo. (Eur J Dent 2012;6:402-407)
\end{abstract}

Key words: Fissure sealant; photoactivation time; ultimate tensile strength; water sorption; water solubility.

1 Department of Dentistry, Potiguar University (Laureate International Universities), Natal, BRAZIL

2 Department of Restorative Dentistry, Piracicaba Dental School, State University of Campinas,

- Piracicaba, SP, BRAZIL

Corresponding author: Dr. Boniek Castillo Dutra Borges R Minas Novas, 390, cs 18 CEP: 59.088-725, Natal, RN, BRAZIL

Tel/Fax: +55 8432072981

boniek.castillodgmail.com

\section{INTRODUCTION}

The use of pit and fissure sealants have been recommended considering the minimally invasive approach. ${ }^{1}$ Their efficacy for the primary and secondary prevention of caries disease, mainly in high-caries-risk patients, has been well demonstrated, so that retention is the main requirement for sealant effectiveness. ${ }^{2-4}$ In view of this, the use of application protocols to increase retention of pit 
and fissure sealants should prolong their benefits on caries prevention and/or arrestment.

Light activated resin-based materials, such sealants and flowable composites, can be used as pit and fissure sealants. ${ }^{5-7}$ Both of them are low-viscosity materials that, nevertheless, present differences in chemical components, which can influence upon their physical strength. ${ }^{7}$ Since physical strength of resin-based dental materials is important for maximizing their clinical performance, ${ }^{8,9}$ obtaining the optimal physical properties of resin-based fissure sealing materials might increase their retention levels after curing.

Ultimate tensile strength (UTS) is a physical property which shows the maximum cohesive resistance to tensile force of a material. ${ }^{10}$ Thus, examination of cohesive strength of fissure sealer materials may predict their resistance to fracture in a clinical environment. It was demonstrated that increasing light exposition time improves the UTS of flowable composites. ${ }^{10}$ However; information is scarce regarding the effect of extending light polymerization time on the UTS of the traditional pit and fissure sealant. Both materials can be used to seal pits and fissures, so that clarifying their UTS may help to predict whether extended photoactivation time would increase the materials' self-fracture.

Another important physical property of dental materials is the water sorption and solubility. The phenomena of sorption and solubility may be precursors to a variety of chemical and physical processes that promote biological concerns as well as having deleterious effects on the structure and function of resin matrixes. ${ }^{11}$ Polymer structure quality such as the degree of conversion and crosslink density resulting from the photo-activation mode may lead to differences in sorption and solubility. ${ }^{12,13}$ It has been demonstrated that a flowable composite presented better degree of conversion and crosslink density than a fissure sealant even under conventional or extended photoactivation time. ${ }^{7}$ However, there is no data concerning water sorption and solubility of flowable composites and traditional fissure sealants when an extended photoactivation time is used to polymerize the samples.

Thus, the aim of this study was to evaluate the effect of extended photoactivation time on ultimate tensile strength, water sorption and solubility of a pit and fissure sealant and a flowable composite. The first hypothesis tested is that extended photoactivation time should improve UTS values and decrease water sorption and solubility for both materials. Another hypothesis is that the flowable composite should present better properties regardless of the extended photoactivation time.

\section{MATERIALS AND METHODS}

Experimental design

The factors under study were materials at two levels la pit and fissure sealant and a flowable composite) and photoactivation time at two levels $(20 \mathrm{~s}$ - following manufacturer's instruction and $60 \mathrm{~s}$ - extended exposure time). UTS, water sorption and solubility tests were performed to characterize the effect of extended light exposure time. The materials' composition and batch numbers are shown in Table 1.

\section{Specimen preparation}

Twenty hourglass samples were prepared from two investigated materials using silicon molds with a $6 \mathrm{~mm}$ length, $1 \mathrm{~mm}^{2}$ constriction areas for the UTS test, while 20 disks $16 \mathrm{~mm}$ diameter, $1 \mathrm{~mm}$ thickness) were prepared from the sealing materials following the experimental conditions. Both materials were injected into silicon molds using the disposable tip supplied by

Table 1. Composition and batch number of the sealants, and irradiance (IR) $\left(\mathrm{mW} / \mathrm{cm}^{2}\right)$ of the curing-light unit used in the study.

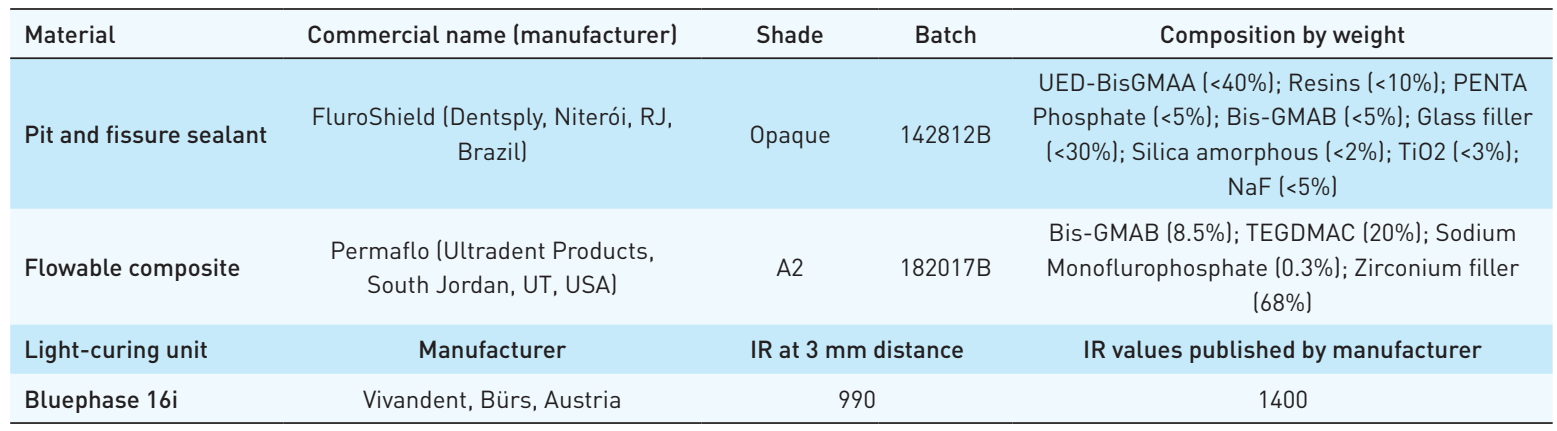


the manufactured under controlled temperature and relative humidity conditions. Materials surfaces were covered with a Mylar strip and then photoactivated for $20 \mathrm{~s}$ or $60 \mathrm{~s}$ with the light-emitting diode (LED) unit Bluephase 16i (Vivandent, Bürs, Austrial set on $3 \mathrm{~mm}$ from the top surface of the sample. ${ }^{7}$ The $8 \mathrm{~mm}$-diameter tip of the LED Bluephase $16 \mathrm{i}$ covered all the samples length during photoactivation. The irradiance of $990 \mathrm{~mW} / \mathrm{cm}^{2}$ reached the top surface of the samples. After polymerization, the samples were removed from the matrices and dry stored in light-proof containers at $37^{\circ} \mathrm{C}$ for 24 hours. $^{14}$ Any specimen with visible voids was discarded.

\section{Ultimate Tensile Strength (UTS) test}

The hourglasses samples were subjected to tension in a universal testing machine (EMIC, São José dos Pinhais, PR, Brazil). They were individually attached to a metallic device with cyanoacrylate-based glue (Locite Super Bonder, Henkel Ltda., São Paulo, SP, Brazil) and tested at a crosshead speed of $0.5 \mathrm{~mm} / \mathrm{min}$ until failure. After failure, they were removed from the metallic device and the cross-sectional area at the site of failure was measured with a digital electronic caliper to the nearest $0.01 \mathrm{~mm}$ (Mitutoyo Corporation, Tokyo, Japan). The results were converted into MPa and expressed as the UTS.

\section{Water sorption and solubility measurement}

This study was performed in compliance with ISO 4049:2000 standard specifications lexcept for the specimen dimensions and curing protocol) as follows. The disks were stored in desiccators containing silica gel at $37^{\circ} \mathrm{C}$. The samples were weighted daily in an analytical balance (Tel Marke, Bel Quimis, São Paulo, SP, Brazil) accurate to $0.001 \mathrm{mg}$, constituting a weighing cycle every 24 hours. The complete cycle was repeated until a constant mass $\left(\mathrm{m}_{1}\right)$ was obtained (two days of no weight change). Thickness (four measurements at four equidistant points on the circumferencel and diameter (two measurements at the right angles) of each specimen were measured using a digital electronic caliper (Mitutoyo Corporation, Tokyo, Japan). Mean values were used to calculate the volume (V) of each specimen (in $\mathrm{mm}^{3}$ ).

Thereafter, the samples were stored in plastic containers with distilled water at $37^{\circ} \mathrm{C}$ for 7 days. The volume of water for immersion was $6 \mathrm{~mL}$ per specimen. Samples were again weighted daily, after being carefully wiped with an absorbent paper. When constant weight was obtained (two days of no weight change), this value was recorded as $m_{2}$. After this weighing, the samples were returned to the first desiccators. The entire mass reconditioning cycle was repeated and the constant mass (two days of no weight change) was recorded as $m_{3}$. The values for water sorption (WS) and solubility (WSB), in micrograms per cubic millimeters, were calculated using the following equations:

WS $=\left(m_{2}-m_{3}\right) / V ;$ WSB $=\left(m_{1}-m_{3}\right) / V$

\section{Statistical analysis}

Exploratory analysis of data indicated that the presuppositions of a parametric test were met. Two-way ANOVA and a Tukey's HSD test at a 5\% of significance were executed to evaluate the impact of two factors under study on UTS, WS and WSB of the investigated materials.

\section{RESULTS}

There was no statistically significant difference in UTS and WS values between the materials and photoactivation time $(P>.05)$. Means and standard deviation of the UTS and WS for each experimental group are shown in Table 2 and 3 respectively. Sol-

Table 2. Ultimate tensile strength means and standard-deviation in MPa for the materials tested at different curing times.

\begin{tabular}{lcc}
\hline Materials & \multicolumn{2}{c}{ Curing times } \\
& $20 \mathrm{~s}$ & $60 \mathrm{~s}$ \\
\hline FluroShield & $37.19 \pm 6.09 \mathrm{Aa}$ & $35.99 \pm 5.97 \mathrm{Aa}$ \\
Permaflo & $39.47 \pm 7.5 \mathrm{Aa}$ & $36.98 \pm 8.57 \mathrm{Aa}$ \\
\hline
\end{tabular}

Different uppercase letters in the rows and lowercase letters in the columns indicate statistically significant differences $(P<.05)$.

Table 3. Water sorption means and standard-deviation in $\mu \mathrm{g} / \mathrm{mm} 3$ for the materials tested at different curing times.

\begin{tabular}{lcc}
\hline Materials & \multicolumn{2}{c}{ Curing times } \\
\hline FluroShield & $24.15 \pm 1.45 \mathrm{Aa}$ & $31.68 \pm 13.18 \mathrm{Aa}$ \\
Permaflo & $30.96 \pm 6.63 \mathrm{Aa}$ & $27.17 \pm 2.42 \mathrm{Aa}$ \\
\hline Different uppercase letters in the rows and lowercase letters in the columns indicate statistically significant differences $(\mathrm{P}<.05)$.
\end{tabular}


ubility value of flowable composite were negative at both times and similar to those presented by Fluroshield at $20 \mathrm{~s}(\mathrm{P}>05)$ but different from those polymerized at $60 \mathrm{~s}(\mathrm{P}<.05)$, as shown in Table 4.

\section{DISCUSSION}

Optimal physical properties of the sealant are important for a successful fissure sealing in the oral environment. Increased mechanical strength of a material placed over pit and fissures can support occlusal stresses during chewing, protecting the adhesive interface and increasing long-term retention. It has been shown that long-term retention of the sealant is a crucial requirement for effective caries prevention ${ }^{2,3}$ and for arresting caries progression. ${ }^{4}$

The first hypothesis tested in this study was rejected. It was demonstrated elsewhere ${ }^{10}$ that the degree of conversion is directly related to the UTS of resin-based materials. Recently, Borges et $\mathrm{al}^{7}$ showed that Permaflo presented a higher degree of conversion (DC) and crosslink density than Fluroshield, and, in addition, that extended photoactivation time increased both physical properties of Permaflo following similar experimental conditions to those established in the present investigation. Thus, it seems to be logical to assume that Permaflo would show higher UTS and that extended light exposure time would increase the UTS of Permaflo. Nevertheless, UTS results obtained in the present work were similar for both materials and there were no demonstrable benefits to extending photoactivation time, thus rejecting the second hypothesis tested. This finding may be explained by the fact that UTS is also influenced by the filler/matrix adhesion. ${ }^{15}$ Possibly, the filler/matrix adhesion in both materials used in this study was similar, so that extended photoactivation time could not increase it. Although the samples may have presented statistically significant differences in the DC after both photoactivation times, these might not be enough to provide differences in UTS.

Water sorption in resin-based materials is a diffusion-controlled process and occurs mainly in the resin matrix. ${ }^{16}$ Higher TEGDMA content in the matrix is responsible for increasing its water sorption. ${ }^{17}$ Permaflo presents a lower monomer content than Fluroshield, but a greater percentage of water soluble TEGDMA. Thus, the high TEGDMA amount present in Permaflo might have compensated the differences in matrix content between the materials, generating similar water sorption means for Permaflo and Fluroshield.

In this study, although UTS and water sorption of the two materials was not different, due to the results concerning DC and crosslink density obtained by a previous investigation, ${ }^{7}$ it can be suggested that using flowable composite and extended photoactivation time to seal pit and fissures may be suitable to decrease some adverse effects. DC of resin-based materials is directly related to the growth of certain caries-related bacteria around material margins. ${ }^{18}$ If a large number of microorganisms is able to grow around the sealant/tooth interface, the possibility of a caries lesion under the sealant increases, leading to a clinical failure.

Solubility of resin-based materials is directly related to their DC. ${ }^{19}$ In this study, the flowable composite Permaflo showed lower solubility than the conventional pit and fissure sealant Fluroshield, and this may be attributed to the higher DC obtained by the flowable composite compared to Fluroshield. ${ }^{7}$ Since solubility is reflected by the amount of leachable unreacted monomers, the higher DC obtained by Permaflo in comparison with Fluroshield previously ${ }^{7}$ reduced its solubility. In this case, the amount of unreacted monomers available for leaching out was lower in Permaflo due to the high percentage of reacted aliphatic $\mathrm{C}=\mathrm{C}$ bonds from the dimethacrylate monomers. ${ }^{20}$ However, negative solubility values obtained by the flowable composite indicate that not all the absorbed water could be removed by the drying process, thus increasing the mass of the material. ${ }^{20,21}$

Water molecules that are firmly bound to polar sites along the polymer network after polymerization of resin-based materials exhibit a high plasticizing effect, thus causing the reduction of the polymers' mechanical properties by altering the mobility of their chain segments. ${ }^{22}$ From a clinical

Table 4. Water solubility means and standard-deviation in $\mu \mathrm{g} / \mathrm{mm}^{3}$ for the materials tested at different curing times.

\begin{tabular}{lcc}
\hline Materials & \multicolumn{2}{c}{ Curing times } \\
\hline FluroShield & $20 \mathrm{~s}$ & $60 \mathrm{~s}$ \\
Permaflo & $0.0 \pm 0.0 \mathrm{Aa}$ & $0.01 \pm 3.1 \mathrm{Aa}$ \\
\hline Different uppercase letters in the rows and lowercase letters in the columns indicate statistically significant differences $(\mathrm{P}<.05)$. & $-4.18 \pm 2.16 \mathrm{Ab}$
\end{tabular}


standpoint, if a fissure sealer material becomes weakened, its long-term retention and consequently its effectiveness can be compromised.

Testing physical properties of materials used as pit and fissure sealants must be encouraged in pediatric dentistry, since their physical properties may predict and justify the clinical performance of these materials. Although the results obtained from previous investigation ${ }^{7}$ showed improved polymer quality after curing for the low viscosity composite, this study indicates that the conventional pit and fissure sealant Fluroshield may present a similar clinical performance to the flowable composite Permaflo.

\section{CONCLUSIONS}

Extended photoactivation time did not increase ultimate tensile strength, nor did it decrease water sorption and solubility of Fluroshield and Permaflo. Fluroshield presented similar ultimate tensile strength and water sorption to Permaflo. However, the conventional fissure sealant showed improved solubility over the flowable composite, since negative solubility values were obtained by Permaflo.

\section{REFERENCES}

1. Borges BC, Borges JS, Araujo LS, Machado CT, Dos Santos AJ, Pinheiro IV. Update on nonsurgical, ultraconservative approaches to treat effectively non-cavitated caries lesions in permanent teeth. Eur J Dent 2011;5:229-236.

2. Griffin SO, Oong E, Kohn W, Vidakovic B, Gooch BF, Barder J, Clarkson J, Fontana MR, Meyer DM, Rozier RG, Weintraub JA, Zero DT. The effectiveness of sealants in managing caries lesions. J Dent Res 2008;87:169-174.

3. Ahovuo-Saloranta A, Hiiri A, Nordblad A, Mäkelä M, Worthington HV. Pit and fissure sealants for preventing dental decay in the permanent teeth of children and adolescents. Cochrane Database Syst Rev 2008;4: DOI: 10.1002/14651858.CD001830.pub3

4. Borges BC, Campos GB, Silveira AD, Lima KC, Pinheiro IV. Efficacy of a pit and fissure sealant in arresting dentin noncavitated caries: a 1-year follow-up randomized singleblind controlled clinical trial. Am J Dent 2010;23:311-316.

5. Corona SAM, Borsato MC, Garcia L, Ramos RP, Palma-Dibb RG. Randomized, controlled trial comparing the retention of a flowable restorative system with a conventional resin sealant: one-year follow-up. Int J Paed Dent 2005;15:44-50.
6. Aguilar FG, Drubi-Filho B, Casemiro LA, Watanabe MG, Pires-de-Souza FC. Retention and penetration of a conventional resin-based sealant and a photochromatic flowable composite resin placed on occlusal pits and fissures. $J$ Indian Soc Pedod Prev Dent 2007;25:169-173.

7. Borges BC, Souza-Junior EJ, Catelan A, Lovadino JR, Santos PH, Paulillo LA, Aguiar FH. Influence of extended light exposure time on degree of conversion and plasticization of materials used as pit and fissure sealants. J Investig Clin Dent 2010;1:151-155.

8. Nalçaci A, Oztan MD, Yilmaz S. Cytotoxicity of composite resins polymerized with different curing methods. Int Endod J 2004;37:151-156.

9. Rode KM, Freitas PM, Loret PR, Powell LG, Turbino ML. Micro-hardness evaluation of micro-hybrid composite resin light cured with halogen light, light-emitting diode and argon ion laser. Lasers Med Sci 2009;24:87-92.

10. Nayif MM, Nakajima M, Foxton RM, Tagami J. Effect of light irradiation time on the mechanical properties of two flowable composites with different initiation systems in bonded and unbonded cavities. Dent Mater J 2007;26:687-693.

11. Sideridou ID, Karabela MM, Vouvoudi EC. Dynamic thermomechanical properties and sorption characteristics of two commercial light cured dental resin composites. Dent Mater 2008;14:737-743.

12. Ferracane JL. Hygroscopic and hydrolytic effects in dental polymer networks. Dent Mater 2006;22:211-222.

13. Lopes LG, Jardim-Filho AV, Souza JB, Rabelo D, Franco EB, Freitas GC. Influence of pulse-delay curing on sorption and solubility of a composite resin. J Appl Oral Sci 2009;17:2731.

14. Borges BC, Silva PR, Catelan A, Aguiar FH. Influence of the curing-light tip distance and material opacity on selected physical properties of a pit and fissure sealant. Pediatr Dent 2011;33:505-509.

15. Yoshida $Y$, Shirai K, Nakayama Y, Itoth M, Okanaki M, Shintani H. Inoue S, Lambrechts P, Vanherle G, Van Meerbeek B. Improved filler-matrix coupling in resin composites. $J$ Dent Res 2002;81:270-273.

16. Braden $M$, Causton BE, Clarke RL. Diffusion of water in composite filling materials. J Dent Res 1976;55:730-732.

17. Sideridou I, Tserki V, Papanastasiou G. Study of water sorption, solubility and modulus of elasticity of lightcured dimethacrylate-based dental resins. Biomaterials 2003;24:655-665.

18. Takahashi Y, Imazato S, Russell RR, Noiri Y, Ebisu S. Influence of resin monomers on growth of oral streptococci. $J$ Dent Res 2004;83:302-306. 
19. da Silva EM, Almeida GS, Poskus LT, Guimarães JG. Relationship between the degree of conversion, solubility and salivary sorption of a hybrid and nanofilled resin composite. J Appl Oral Sci 2008;16:161-166.

20. Berger SB, Cavalli V, Palialol AR, Giannini M. Characterization of water sorption, solubility and filler particles of lightcured composite resins. Braz Dent J 2009;20:314-318.

21. Janda R, Roulet JF, Latta M, Rüttermann S. Water sorption and solubility of contemporary resin-based filling materials. J Biomed Mater Res Part B: Appl Biomater 2007;82B:545551.

22. Malacame J, Carvalho RM, de Goes MF, Svizero N, Pashley DH, Tay FR, Yiu CK, Carrilho MR. Water sorption/solubility of dental adhesive resins. Dent Mater 2006;22:973-980. 